\title{
Study of biological activity of Tricholoma equestre fruiting bodies and their safety for human
}

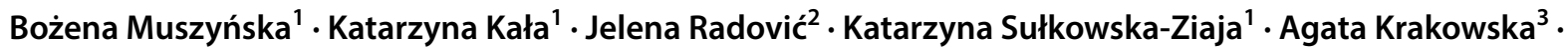 \\ Joanna Gdula-Argasińska ${ }^{4} \cdot$ Włodzimierz Opoka ${ }^{3} \cdot$ Tatjana Kundaković $^{2}$
}

Received: 11 June 2018 / Revised: 3 July 2018 / Accepted: 6 July 2018 / Published online: 31 July 2018

(c) The Author(s) 2018

\begin{abstract}
One of the species of mushrooms authorized for sale in some countries—Tricholoma equestre — can be harmful, and its excessive consumption can lead to serious health problems. Many authors have pointed to the relationship between the consumption of the T. equestre and the occurrence of rhabdomyolysis. The aim of this study was to analyze the composition of biologically active substances in the T. equestre fruiting bodies, and determine their biological activity. The main aim of the analyses performed in the present study was to determine whether the T. equestre is safe or dangerous for consumption by humans. The obtained results, in addition to the existing reports on poisoning caused by T. equestre consumption, are another reason to not take the risk of consuming the fruiting bodies of this species, as the natural environment is rich in other species of edible mushrooms that are not only tasty, but also exhibit healing properties.
\end{abstract}

Keywords Antioxidant activity $\cdot$ Pro-inflammatory activity $\cdot$ Edible mushrooms $\cdot$ Tricholoma equestre $\cdot$ Rhabdomyolysis

\section{Introduction}

Edible mushrooms have been valued for years because of their dietary qualities and healing properties. In recent years, the list of edible and medicinal mushrooms has been expanded [1]. In Poland, 44 species of edible and medicinal mushrooms were identified. They were included in the official list of "fungi authorized for the market or production of mushroom products and foods containing mushrooms," which is an annexure to the Ordinance of the Minister of Health of 17 May 2011. However, some scholars have reported that one of the widely admitted species on the list-Tricholoma equestre (also referred to as Tricholoma

Bożena Muszyńska

muchon@poczta.fm

1 Department of Pharmaceutical Botany, Faculty of Pharmacy, Jagiellonian University Medical College, Kraków, Poland

2 Department of Pharmacognosy, Faculty of Pharmacy, University of Belgrade, Belgrade, Serbia

3 Department of Inorganic and Analytical Chemistry, Faculty of Pharmacy, Jagiellonian University Medical College, Kraków, Poland

4 Department of Radioligands, Faculty of Pharmacy, Jagiellonian University Medical College, Kraków, Poland flavovirens) — can be harmful, and its excessive consumption can lead to health problems [1-7].

Many authors have pointed to the relationship between the consumption of the T. equestre fruiting bodies and the occurrence of rhabdomyolysis, i.e., rapid decomposition of transverse striated muscle tissue [1,4-7]. Rhabdomyolysis is a clinical condition, whose very frequent consequence is death. The characteristic symptoms include general weakness, muscle pain, sweating without symptoms of fever, and dark urine color $[1,4,5]$. No other possible causes of rhabdomyolysis (viral, parasitic, immunological diseases, previous injuries, or adverse drug reactions) were found in patients, whose cases were analyzed after they had consumed large amounts of the T. equestre fruiting bodies [1, 4-7].

In several European countries, e.g., in France or Germany, the T. equestre species is considered dangerous because of the fact that in the years 1992-2016, there were numerous cases of poisoning as a result of its consumption, including several deaths. Some cases of the above-mentioned fatal poisoning were also reported in Poland [1, 4, 5, 7]. Fatal cases were reported as a result of the repeated consumption of significant amounts of this species of fruiting bodies as part of several subsequent meals [4-6, 8]. Here, repeated consumption is defined as a triple meal consisting of $100-400 \mathrm{~g}$ 
of appropriately prepared fresh fruiting bodies $[7,8]$. The first 12 cases of poisoning after the consumption of the $T$. equestre fruit bodies were found in France in 1992-2001 $[2,4,7-9]$.

After these events, experiments were carried out involving the administration of a $T$. equestre extract to laboratory animals (mice), which confirmed its toxic activity, manifesting in the increase in the blood levels of the biochemical markers of toxicity: plasmatic creatine kinase (CK), bilirubin, alanine aminotransferase (ALAT), or aspartate aminotransferase (AST). In addition, the animals had diarrhea, showed reduced motor activity, and had disintegrated muscle fibers. Unfortunately, it was not possible to identify a specific myolytic toxin, which was responsible for rhabdomyolysis; this also made it impossible to investigate the mechanism of this toxin action. It turned out that this species, in addition to its myolytic activity, exhibits a strong cardio- and hepatotoxic effect, which contributes to the impression of rhabdomyolysis $[1,4,5,7,8]$. Studies conducted on mice confirmed the toxicity, but they did not definitively confirm that the consumption of $T$. equestre was the cause of the fatal poisoning; nevertheless, the authors warned against collecting, buying, and above all, repeatedly consuming the fruiting bodies of this species [5, 8].

On the basis of mycorrhiza, two varieties of fruiting bodies are distinguished within the T. equestre species: one showing symbiosis with Populus sp., and the other with Betula sp. This may be the reason for the differences in the content of biologically active substances. In Poland, this species is considered edible, while in France, its distribution and consumption has been banned since 2005 [5]. Certainly, there have been many reports on the positive effects of the consumption of T. equestre on human health. The anticancer activity was demonstrated for flavomannin-6,6'-dimethyl ether isolated from the fruiting bodies of this species. It was demonstrated that even temperature-treated fungi are a good source of this compound and have a positive antiproliferative effect on the $\mathrm{CaCo}-2$ colorectal cancer cells [10]. T. equestre is also a source of zinc-an element that is necessary for the appropriate functioning of the human body [11]. It is a species in which unsaturated fatty acids were determined. Therefore, the prevention of cardiovascular diseases (e.g., hypertension and atherosclerosis) is indirectly attributed to this species. Among the fatty acids, T. equestre contains oleic acid (a popular component of olive oil) in the largest amounts, whose most important activity is to counteract hypercholesterolemia. Moreover, the presence of linoleic acid, which is biologically significant for the body, was determined in this species [12].

The aim of this study was to analyze the composition of biologically active substances in the T. equestre species, including bioelements (in vitro conditions imitating natural digestive processes), profile fatty acids, identify the presence of sterols, and determine the antioxidant, antibacterial, antifungal, and anti-inflammatory activity. The main aim of the analyses performed in the present study was to determine whether the T. equestre fruiting bodies are safe or dangerous for consumption by humans.

\section{Materials and methods}

\section{Mushroom materials}

In the present work, the fruiting bodies of T. equestre (L.) P. Kumm. (Tricholomataceae) also known as T. flavovirens were used. These fruiting bodies were collected from the mixed forests of South Poland (in the vicinity of Kraków and Rzeszów) between 2014 and 2016. The taxonomic identification of the sporocarps was performed using the method proposed by Knudsen and Vesterholt and the key (http://www.mycokey.com) developed by Muszyńska [13]. Representative voucher specimens number KB/Tr2016 were deposited at the Jagiellonian University Collegium Medicum (Kraków, Poland) in the Department of Pharmaceutical Botany. The mushroom materials were frozen and then lyophilized (Freezone 4.5 . Labconco; $-40{ }^{\circ} \mathrm{C}$ ) to obtain the mushroom samples for further analyses.

\section{Reagents}

Cyclohexane and dichloromethane were purchased from Thermo Fisher Scientific, Life Technologies (Waltham, MA, USA); methanol, 1,1-diphenyl-2-picrylhydrazyl, and FAME were obtained from Sigma (St. Louis, MO, USA). Ascorbic acid was purchased from Acros (Geel, Belgium); rutin from Fluka (Buchs, Switzerland); gallic acid from Roth (Karlsruhe, Germany); petrolether from Centrohem (Stara Pazova, Serbia); pepsin and bile salts from BTL (Łódź, Poland); $\mathrm{MgCl}_{2}$ from Chempur (Kraków, Poland); $\mathrm{NaHCO}_{3}$ from PPH Golpharm (Kraków, Poland); KOH and $\mathrm{NaCl}$ from Alfa Aesar® (Kandel, Germany); $\mathrm{CaCl}_{2}$ from Pharma Zentrale $\mathrm{GmbH}$ (Herdecke, Germany); $\mathrm{HCl}$ pancreatic extract, $\mathrm{HNO}_{3}$ concentrated, Suprapur ${ }^{\circledR}$, and hydrogen peroxide 30\% from Merck (Darmstad, Germany); $\mathrm{KHCO}_{3}, \mathrm{Na}_{2} \mathrm{HPO}_{4}, \mathrm{C}_{6} \mathrm{H}_{8} \mathrm{O}_{7}$, and $\mathrm{K}_{2} \mathrm{HPO}_{4}$ from Polish Company of Chemistry (Gliwice, Poland); and zinc (II) ion content standards at a concentration of $1 \mathrm{~g} / \mathrm{L}$ from Regional Office of Measures (Łódź, Poland). Quadrupledistilled water with a conductivity of less than $1 \mu \mathrm{S} / \mathrm{cm}$ was obtained using an S2-97A2 distillation apparatus (Chemland, Stargard Szczeciński, Poland). 


\section{Digestion process}

Artificial digestive juices were prepared according to the methodology previously presented by Kała et al. (2017). Artificial saliva $(\mathrm{pH}=6.8$. $): 100 \mathrm{~mL} \mathrm{KH}_{2} \mathrm{PO}_{4}$ at a concentration of $25 \mathrm{mmol} / \mathrm{L}, 100 \mathrm{~mL} \mathrm{Na}_{2} \mathrm{HPO}_{4}$ at a concentration of $24 \mathrm{mmol} / \mathrm{L}, 100 \mathrm{~mL} \mathrm{KHCO}_{3}$ at a concentration of $150 \mathrm{mmol} / \mathrm{L}, 100 \mathrm{~mL} \mathrm{MgCl}_{2}$ at a concentration of $1.5 \mathrm{mmol} / \mathrm{L}, 6 \mathrm{~mL}$ citric acid at a concentration of $25 \mathrm{mmol} / \mathrm{L}$, and $100 \mathrm{~mL} \mathrm{CaCl}_{2}$ at a concentration of $15 \mathrm{mmol} / \mathrm{L}$ were added to the flask and the volume was made up to $1000 \mathrm{~mL}$ with four-time distilled water. Artificial stomach juice ( $\mathrm{pH}=2.0$ ) was prepared: $2.0 \mathrm{~g} \mathrm{NaCl}$ and $3.2 \mathrm{~g}$ pepsin were dissolved in four-time distilled water. Then, $80 \mathrm{~mL} \mathrm{HCl}$ at a concentration of $1 \mathrm{~mol} / \mathrm{L}$ was added, and the volume was made up to $1 \mathrm{~L}$ using four-time distilled water. Artificial intestinal juice $(\mathrm{pH}=8.0)$. Briefly, $20 \mathrm{mg}$ pancreatic extract, $120 \mathrm{mg}$ bile salt, and $8.4 \mathrm{~g} \mathrm{NaHCO}_{3}$ were dissolved in four-time distilled water and the volume was made up to $1 \mathrm{~L}$ using four-time distilled water [3].

Lyophilized T. equestre fruiting bodies were homogenized in a mortar and weighed at $0.5 \mathrm{~g}$. The weighed material was placed in the flasks and wet with $2 \mathrm{~mL}$ of saliva solution. Next, $20 \mathrm{~mL}$ of artificial gastric juice was added to the flasks, and incubation was carried out in the Gastroel-2014 apparatus (an apparatus imitating natural digestive processes, constructed for the needs of the experiment) for two different time periods (60 and $120 \mathrm{~min}$ ). After the appropriate extraction time, the samples were decanted. Then, the extract was separated, and the partially digested material was treated with $20 \mathrm{~mL}$ of artificial intestinal juice. The incubation time in the artificial intestinal juice was $150 \mathrm{~min}$ for all the examined samples. Thereafter, the extracts were separated from the digested material and transferred to the previously prepared samples. All of the extracts were filtered using membrane filters (Millex, Millipore Corporation, USA).

\section{Determination of bioelements using F-AAS method}

To determine the concentration of metals $(\mathrm{Ca}, \mathrm{Cu}, \mathrm{Fe}, \mathrm{Mg}$, and $\mathrm{Zn}$ ) in the collected T. equestre fruiting bodies, the samples were subjected to mineralization. For this purpose, $0.2 \mathrm{~g}$ of the homogenized material was weighed with an accuracy of $0.01 \mathrm{~g}$. The prepared samples were transferred to Teflon vessels to which $2 \mathrm{~mL}$ of perhydrol and $4 \mathrm{~mL}$ of concentrated nitric $(\mathrm{V})$ acid solution were added. The mineralization process was carried out in a Magnum II microwave from ERTEC in three phases. The clear solutions obtained after mineralization were transferred to quartz evaporators and evaporated on a heating plate at $150{ }^{\circ} \mathrm{C}$. The residue was quantitatively transferred using four-time distilled water into $10-\mathrm{mL}$ volumetric flasks. The concentrations of the analyzed metals in the mineralized samples and extracts obtained at the release test stage were determined using atomic absorption spectrometry (flame technique-F-AAS). The atomic absorption spectrometer from Thermo Scientific Model iCE 3500 (UK) was used for all the measurements. Each sample was tested in three independent replicates, and the results were presented as mean values (Fig. 1a-c).

\section{Sample preparation for DPPH assay, total phenolic content, fatty acids and sterols composition, and antimicrobial activity}

For the preparation of cyclohexane, dichloromethane, methanol, and aqueous extracts, we used $41.6 \mathrm{~g}$ of powdered mushroom. The aqueous extract was prepared with $14 \mathrm{~g}$ of dried, powdered mushroom and $280 \mathrm{~mL}$ of distillated water. Extraction was carried out by shaking and heating the samples in a water bath for $30 \mathrm{~min}$ at $100{ }^{\circ} \mathrm{C}$. After the extraction, the aqueous extract was filtrated, and the solvent was evaporated. Then, $280 \mathrm{~mL}$ of cyclohexane was added to $27.6 \mathrm{~g}$ of powdered mushroom, and extraction was carried out by shaking the samples at room temperature. The procedure was repeated with dichloromethane and methanol. The solvents were evaporated under low pressure and stored at $4{ }^{\circ} \mathrm{C}$.

\section{DPPH assay}

The ability of methanol and the aqueous extracts to scavenge free radicals was measured using the DPPH test. This ability is a measure of antioxidant activity. The absorbance of the solution was measured at $517 \mathrm{~nm}$, and the percentage inhibition of the DPPH radicals was calculated. Each measurement was performed in triplicate. The results were expressed as a concentration of the test sample that reduced $50 \%$ of the DPPH radicals $\left(\mathrm{IC}_{50}\right.$ value). The DPPH reagent (1,1-diphenyl-2-picrylhydrazyl) was made ex tempore in concentration of $0.5 \mathrm{mmol} / \mathrm{L}$, by dissolving $9.86 \mathrm{mg}$ of $\mathrm{DPPH}$ in $50 \mathrm{~mL}$ of methanol.

A $30-\mathrm{mg} / \mathrm{mL}$ stock solution of the methanol extract was prepared, and for the aqueous extract, the concentration was $40 \mathrm{mg} / \mathrm{mL}$. Then, different volumes of these solutions $(10-100 \mu \mathrm{L})$ were mixed with methanol to obtain a total volume of $2 \mathrm{~mL}$, and $0.5 \mathrm{~mL}$ of DPPH reagent was then added. These solutions were shaken well and incubated in dark for $30 \mathrm{~min}$. Then, the absorbance was measured.

\section{Total phenolic content}

The total content of phenols in methanol and the aqueous extracts was determined spectrophotometrically. Absorbance was measured at $725 \mathrm{~nm}$. A series of gallic acid dilutions $(1-10 \mathrm{mg} / \mathrm{mL})$ were made, the absorbance was measured, 
Fig. 1 a Total metal content $(\mathrm{mg} / 100 \mathrm{~g}$ dry weight $)$ in biomass. b Total metal content (mg/100 g dry weight) after extraction to stomach juice after 60 and 120 min. c Total metal content (mg/100 g dry weight) after extraction to intestinal juice after incubation for 60 and $120 \mathrm{~min}$ in stomach juice
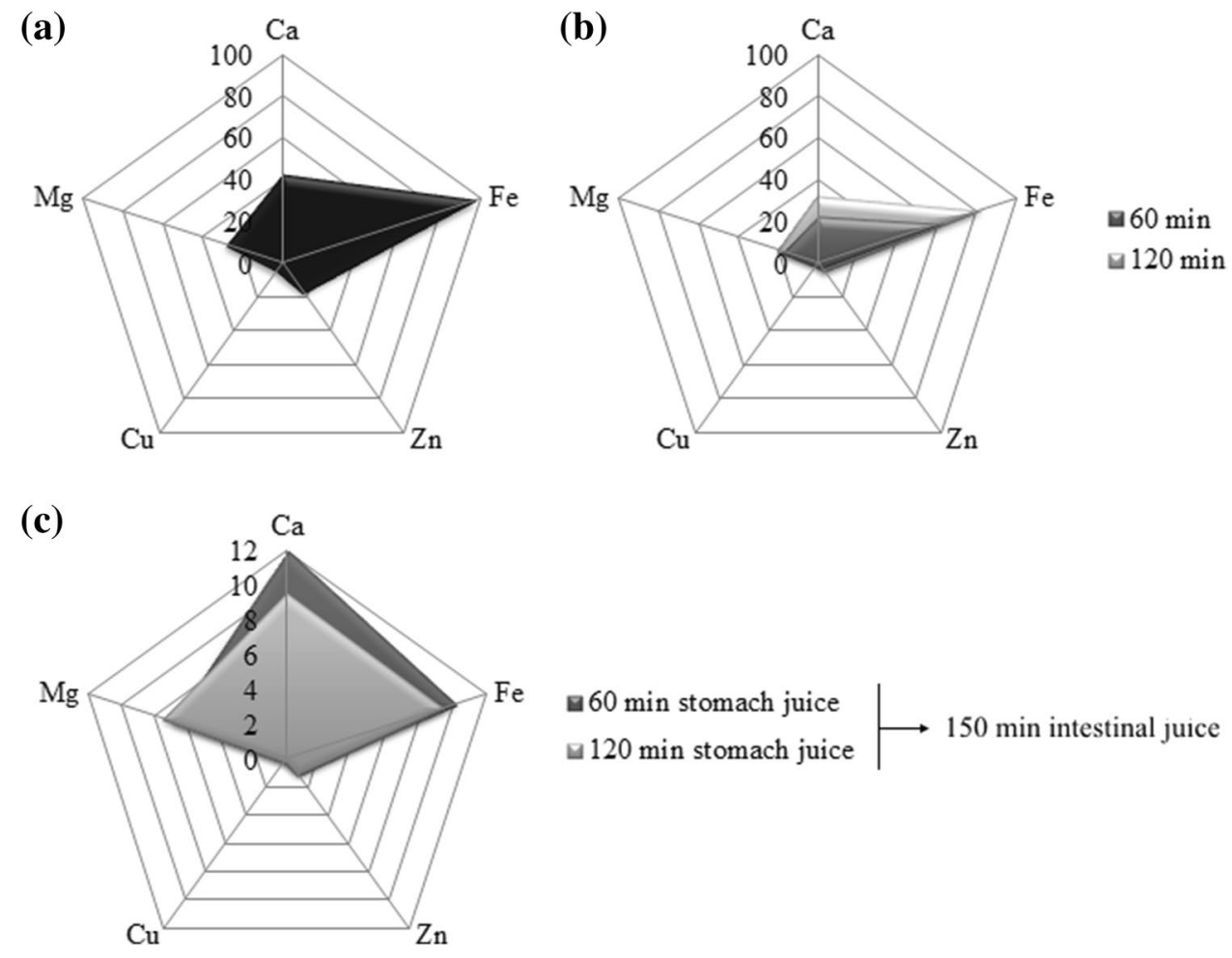

and the calibration curve was drawn. The content of polyphenols was expressed as mass $(\mu \mathrm{g})$ of the standard substance (gallic acid, GA) per unit mass (mg) of the extract.

\section{Fatty acid composition}

To study the chemical composition of the prepared extracts, the fatty acids and sterol compositions of the cyclohexane extract were measured using GC-MS. Saponification was achieved by adding $50 \% \mathrm{KOH}$ at $90{ }^{\circ} \mathrm{C}$ for $60 \mathrm{~min}$. The unsaponifiable fraction was separated using petrol ether and submitted to GC and GC-MS analyses. Fatty acids were esterified using $98 \% \mathrm{H}_{2} \mathrm{SO}_{4} / \mathrm{MeOH}$ anhydrous to obtain fatty acid methyl esters (FAMEs).

The GC and GC-MS analyses were performed on an Agilent $6890 \mathrm{~N}$ Gas Chromatograph equipped with a split/ splitless injector $\left(260^{\circ} \mathrm{C}\right)$, an FID detector, and a capillary column (Agilent J\&W HP-88, $100 \mathrm{~m} \times 0.25 \mathrm{~mm}, 0.20-\mu \mathrm{m}$ film thickness), and coupled with Agilent 5975C MS Detector operating in the EI mode at $70 \mathrm{eV}$. The carrier gas was $\mathrm{He}$, and the flow was $1.2 \mathrm{~mL} / \mathrm{min}$. The oven temperature was initially maintained at $140{ }^{\circ} \mathrm{C}$ for $5 \mathrm{~min}$, then increased linearly from 140 to $240{ }^{\circ} \mathrm{C}$ at $4{ }^{\circ} \mathrm{C} / \mathrm{min}$, and finally held at $240{ }^{\circ} \mathrm{C}$ for $10 \mathrm{~min}$. The FID and MSD transfer line temperatures were 260 and $250{ }^{\circ} \mathrm{C}$, respectively. The split ratio was $1: 25$, and the injected volume was $1 \mu \mathrm{L}$ of a $1 \%$ solution of the FAME in dichloromethane (HPLC purity). All the experiments were performed in triplicate.
The identification of the FAMEs was based on the comparison of their retention times (Rt) and mass spectra to those of the representative standards ran under the same chromatographic conditions (SupelcoTM 37 Component FAME Mix) and to those from the NIST/NBS 05 and Wiley (8th edition) Libraries, and the literature. Relative percentages of the compounds were calculated on the basis of the peak areas from the FID data.

\section{Sterol composition}

The GC analysis was performed on an Agilent 6890N GC system equipped with 5975 MSD and FID, using an HP-5 MS column $(30 \mathrm{~m} \times 0.25 \mathrm{~mm} \times 0.25 \mu \mathrm{m})$. The injection volume was $1 \mu \mathrm{L}$, and the injector temperature was $280^{\circ} \mathrm{C}$ with a 10:1 split ratio. Helium was used as the carrier gas ( $1.0 \mathrm{~mL} / \mathrm{min}$; constant flow mode). The column temperature was linearly programmed in the range of $60^{\circ} \mathrm{C}-280{ }^{\circ} \mathrm{C}$ at a rate of $3{ }^{\circ} \mathrm{C} / \mathrm{min}$ and held at $280^{\circ} \mathrm{C}$ for $20 \mathrm{~min}$. The transfer line was heated at $250{ }^{\circ} \mathrm{C}$. The FID detector temperature was $300{ }^{\circ} \mathrm{C}$. EI mass spectra $(70 \mathrm{eV})$ were acquired in the $\mathrm{m} / \mathrm{z}$ range of 35-550. The identification of the compounds was based on the comparison of the mass spectra from the databases (NIST/NBS 05, Wiley Libraries, 8th edition).

\section{Antimicrobial activity}

The antimicrobial activity of aqueous, methanol, cyclohexane, and dichloromethane extracts was determined using 
the broth microdilution method. All the four extracts were dissolved in DMSO to obtain concentrations of 500, 250, $125,62.5$, and $31.25 \mu \mathrm{g} / \mathrm{mL}$. For this test, seven types of bacteria and one species of yeast were used. All of the bacteria were prepared in the Miller Hinton liquid medium, and the yeast was prepared in the Saburo liquid medium, and right before the use, in both the liquid mediums, tetrazolium chloride (TTC) was added. Every hole in the microtiter plate contained $100 \mu \mathrm{L}$ of the extract and $100 \mu \mathrm{L}$ of the bacteria culture, except for the last two holes, which contained only $200 \mu \mathrm{L}$ of the bacteria culture as the negative control. All the plates were incubated for 2 days at $37^{\circ} \mathrm{C}$. After the incubation, results were obtained visually as the MIC-minimal inhibitory concentration. The MICs of ampicillin and amikacin were determined in parallel experiments as a positive control.

\section{Anti-inflammatory activity}

\section{Cell cultures}

Human lung carcinoma epithelial A549 cells (American Type Culture Collection CCL-185) were cultured in an F $12 \mathrm{~K}$ medium with $10 \% \mathrm{FBS}$, penicillin $(100 \mathrm{IU} / \mathrm{mL})$, and streptomycin $(100 \mathrm{mg} / \mathrm{mL})$ (ATCC, Manassas, VA, USA). The cells were maintained at $37{ }^{\circ} \mathrm{C}$ in a humidified atmosphere that contained $5 \% \mathrm{CO}_{2}$ and were seeded into six-well plates (Sarstedt, Hannover, Germany), at a density of $5 \times 10^{5}$ cells/well in $2 \mathrm{~mL}$ of the medium. The A549 cells $(24 \mathrm{~h}$ after seeding) were activated with LPS and/or incubated with $20 \mu \mathrm{L}$ of $T$. equestre extract (dissolved in ethanol) for $24 \mathrm{~h}$. The control cultures received the same concentration of ethanol (the final content did not exceed $0.01 \%$, v/v) as the experimental cells did.

\section{Western blot analysis}

The cell lysate was prepared using the M-PER mammalian protein extraction reagent (Thermo Scientific, Waltham, MA, USA) with protease inhibitor cocktail set III (Calbiochem, Merck, Darmstadt, Germany) as described below [14]. We used the following primary antibodies: COX-2, cPGES, Nrf2, and B-actin (GeneTex, Irvine, CA, USA) diluted to the ratio $1: 1000$. The secondary antibody was anti-rabbit IgG (HRP) diluted to 1:2000 (ThermoFisher Scientific, Waltham, MA, USA). The proteins were detected using a Western blot detection kit called Clarity Western ECL Luminol Substrate (Bio-Rad, Hercules, CA, USA). The integrated optical density of the bands was quantified using Chemi Doc Camera with the Image Lab software (Bio-Rad, CA, USA).

\section{Results and discussion}

\section{Bioelement analysis}

To determine the actual amounts of metals available to the human body, the release of selected bioelements to artificial digestive juices was studied. Extraction was carried out in the Gastroel-2014 apparatus under conditions imitating those that prevail naturally in the human body (a suitable temperature of $37^{\circ} \mathrm{C}$ and peristaltic movements) [3].

The concentrations of $\mathrm{Ca}, \mathrm{Cu}, \mathrm{Fe}, \mathrm{Mg}$, and $\mathrm{Zn}$ metals in the T. equestre fruiting bodies and in extracts obtained by digestion in artificial digestive juices were determined using the atomic absorption spectrometry (F-AAS) method, which because of the high accuracy, precision, and repeatability of the measurement is one of the most commonly used analytical methods. Optimized conditions of sample mineralization in combination with the F-AAS method enabled an effective analysis of elements in fruiting bodies and extracts obtained from artificial digestive juices.

The experiment revealed that the T. equestre fruiting bodies contain macronutrients such as calcium $(43 \mathrm{mg} / 100 \mathrm{~g}$ dry matter) and magnesium $(28.6 \mathrm{mg} / 100 \mathrm{~g}$ dry matter $)$, and microelements as copper $(4.9 \mathrm{mg} / 100 \mathrm{~g}$ dry matter), iron (98 mg/100 g dry matter), and zinc ( $17 \mathrm{mg} / 100 \mathrm{~g}$ dry matter) (Fig. 1a). After the digestion of fruiting bodies in digestive juices, the quantities of bioelements determined were considerably smaller than those in the original biomass.

According to these data, an intake of $100 \mathrm{~g}$ of lyophilized biomass from T. equestre does not satisfy the daily requirement for calcium and magnesium for both women and men (according to RDA standards, Institute of Medicine, 2001) (Fig. 1a). However, the present experiment revealed that the determined amounts of micronutrients- $\mathrm{Cu}, \mathrm{Fe}$, and $\mathrm{Zn}$-after extraction to artificial digestive juices from the $T$. equestre fruiting bodies were sufficient to supplement the deficiency of these elements in the human body (Fig. 1a) [3]. Furthermore, the examined micronutrients were released more effectively to gastric juice than to intestinal juice. In addition, the amount of metals released to the artificial gastric juice depended on the time of incubation and increased with its elongation. Thus, in the case of copper, $60 \mathrm{~min}$ after digestion in the artificial gastric juice, the content of this element was on average only $0.59 \mathrm{mg} / 100 \mathrm{~g}$ dry matter, and after the incubation time was extended to $120 \mathrm{~min}$, it was already $1.29 \mathrm{mg} / 100 \mathrm{~g}$ dry matter. Note that the daily requirement for this element for men is $0.89 \mathrm{mg} / 24 \mathrm{~h}$ (Fig. 1b). For the other elements, a more effective release to gastric juice was also demonstrated along with the prolongation of the incubation time, and the amounts determined were $63 \mathrm{mg} / 100 \mathrm{~g}$ dry matter for Fe and $2.67 \mathrm{mg} / 100 \mathrm{~g}$ dry matter for Zn (Fig. 1b, c). 


\section{DPPH assay}

The $\mathrm{IC}_{50}$ value of the methanol extract was $1500.2 \pm 62.73 \mu \mathrm{g} / \mathrm{mL}$, and the $\mathrm{IC}_{50}$ value of the aqueous extract was $1901.8 \pm 144.25 \mu \mathrm{g} / \mathrm{mL}$. In Table 1 , the $\mathrm{IC}_{50}$ values of the tested extracts are present, as well as the $\mathrm{IC}_{50}$ value of a few standard substances. All the reference substances in Table 1 show a strong antioxidant potential; lower $\mathrm{IC}_{50}$ values indicate better activity [15]. Among the examined compounds, gallic acid exhibited the best antioxidant activity (Table 1). The extracts obtained from the T. equestre species, in the form of both aqueous and methanol solutions, turned out to be considerably weak antioxidants. The methanolic extract showed more than 400-fold lower antioxidant potential than the standard substances and their average $\mathrm{IC}_{50}$ values, while the aqueous solution was more than 500-fold weaker.

There are some reports on the antioxidant potential of $T$. equestre due to the presence of phenolic compounds or $\beta$-carotene. However, it turns out that this activity is relatively low, which may indicate that the content of compounds with antioxidant activity is not high or, in addition to substances with antioxidant activity, there are those that intensify the oxidation processes [16]. At the same time, the author describing this species indicated that $T$. equestre belongs to the group of non-edible fungi [16]. Compared with other species of edible fungi, e.g., Agaricus brasiliensis $\left(\mathrm{IC}_{50}=3000 \mu \mathrm{g} / \mathrm{mL}\right.$ ), or popular Asian species Hypsizigus marmoreus (ethanolic extract, $\mathrm{IC}_{50}=4190 \mu \mathrm{g} / \mathrm{mL}$; hot water extract, $\mathrm{IC}_{50}=6480 \mu \mathrm{g} / \mathrm{mL}$ ), the antioxidant activity of the examined extracts is relatively high for $T$. equestre $[17,18]$. In turn, the $\mathrm{IC}_{50}$ values for Leucopaxillus giganteus, Sarcodon imbricatus, and Agaricus arvensis (methanol extracts) are 1440,1670 , and $3500 \mu \mathrm{g} / \mathrm{mL}$, respectively; therefore, the results for the first two species are comparable to those for T. equestre [19]. For the popular wood decay fungi species Fomitopsis pinicola and Laetiporus sulphureus, the $\mathrm{IC}_{50}$ values obtained in the DPPH test are 130 and $60 \mu \mathrm{g} / \mathrm{mL}$ of methanol extract, respectively, indicating a considerably stronger antioxidant potential than that of the edible species, including $T$. equestre [20].

Table $1 \mathrm{IC}_{50}$ values of tested extracts and standard substances (DPPH assay)

\begin{tabular}{lc}
\hline Sample & $\mathrm{IC}_{50}(\mu \mathrm{g} / \mathrm{mL})$ \\
\hline Methanol extract of T. equestre & 1500.2 \\
Aqueous extract of $T$. equestre & 1901.8 \\
Ascorbic acid & 3.80 \\
Rutin & 5.57 \\
Gallic acid & 1.50 \\
Quercetin & 2.75 \\
\hline
\end{tabular}

\section{Total phenolic content}

The phenolic compounds are the important group of biological active compounds synthesized by mushrooms. Their biological activity is related to antioxidant activity and thus ability to protect important cellular structures such as cellular membranes, structural proteins, enzymes, and cell membrane lipids. The most common phenolic acids produced by mushrooms are gallic, ferulic, $p$-hydroxybenzoic, $p$-coumaric, caffeic, protocatechuic, syringic, and vanillic acids [21].

The total phenolic content in methanol and the aqueous extracts of $T$. equestre was calculated using the calibration curve of gallic acid (0.999). The total content of phenols in the methanol extract was $14.07 \pm 0.38 \mu \mathrm{g} \mathrm{GA} / \mathrm{mg}$ of extract, and the total content of phenols in the aqueous extract was $12.07 \pm 0.18 \mu \mathrm{g} \mathrm{GA} / \mathrm{mg}$ of extract. Thus, we concluded that the methanol extracts of $T$. equestre were richer in phenols than the aqueous extracts. Note that phenolic compounds have redox properties; thus, they can play the role of antioxidants. Therefore, the assessment of the total phenol concentration provides information about the antioxidant potential of specific raw materials [21]. For most fungal extracts, a clear quantitative relationship between the total phenol content and the demonstrated antioxidant potential is observed [22]. Compared with some species of fungi, $T$. equestre has a relatively total high phenol content. The total phenol content of $6.29,3.76,2.83,10.65$, and $4.27 \mu \mathrm{g} \mathrm{GA} /$ $\mathrm{mg}$ was determined in the methanol extracts of L. giganteus, S. imbricatus, A. arvensis, Agaricus bisporus, and Pleurotus ostreatus, respectively $[19,20]$. In contrast, for the $H$. marmoreus species, the total phenol content is $12.9 \mu \mathrm{g} \mathrm{GA} / \mathrm{mg}$ of extract for ethanol extracts and $19.2 \mu \mathrm{g} \mathrm{GA} / \mathrm{mg}$ of extract for hot aqueous extracts [17]. Data are also available for the total phenol content in the methanol extracts of wood decay fungi species $-F$. pinicola (387.70 $\mu \mathrm{g} \mathrm{GA} / \mathrm{mg}$ of extract) and Piptoporus betulinus (34.94 $\mu \mathrm{g} \mathrm{GA} / \mathrm{mg}$ of extract) —and in ethanol extracts-Phellinus gilvus $(2.50 \mu \mathrm{g} \mathrm{GA} / \mathrm{mg}$ of extract), Fomes fomentarius (47.29 $\mu \mathrm{g} \mathrm{GA} / \mathrm{mg}$ of extract), F. pinicola (29.27 $\mu \mathrm{g} \mathrm{GA} / \mathrm{mg}$ of extract), and L. sulphureus (9.78 $\mu \mathrm{g} \mathrm{GA} / \mathrm{mg}$ of extract) [20]. Thus, variability can be observed in terms of the total amount of phenols released to the aqueous and alcohol extracts (higher levels of phenolic compounds in one species were determined in the methanol and ethanol extracts, and in the others, in the aqueous extracts). Species variability is also important, as inedible species (wood decay ones) usually are characterized by a higher content of phenolic compounds [17, 19, 20].

\section{Fatty acid composition}

Fatty acids contained in mushrooms are capable of supporting anti-inflammatory processes in the humans due to the large share of unsaturated fatty acids $[12,23]$. 
An analysis of the content of the determined fatty acids revealed that this species has a favorable quantitative ratio of unsaturated-to-saturated fatty acids (59.41-40.59\%). Palmitic, oleic, and linoleic acids were determined in the highest amounts $(28.84,28.59$, and $28.29 \%$ of the total content, respectively) (Table 2). Other analyses of fatty acids in the T. equestre species indicated that the ratio of unsaturatedto-saturated fatty acids is as much as $97.24-2.76 \%$, which further increases the value of this species [12]. To ensure the appropriate functioning of the human body, it is necessary to have a balance between saturated and unsaturated fatty acids in one's daily diet $[12,23]$. On the basis of the obtained results, we concluded that the $T$. equestre species is a good natural source of unsaturated fatty acids and can be a valuable component of everyday diet. However, note that compared with the other edible species, such as Cantharellus cibarius, or Suillus luteus, the total amount of fatty acids in T. equestre is significantly low [12].

Table 2 Fatty acid composition in Tricholoma equestre species

\begin{tabular}{llll}
\hline Fatty acid & Fatty acid & $\%$ & STD \\
\hline C14:0 & Myristic acid & 0.31 & 0.05 \\
C15:0 & Pentadecanoic acid & 2.11 & 0.18 \\
C16:0 & Palmitic acid & 28.84 & 2.08 \\
C17:0 & Heptadecanoic acid & 0.16 & 0.01 \\
C18:0 & Stearic acid & 7.58 & 0.71 \\
C18:1n9c & Oleic acid & 28.59 & 1.71 \\
C 18:1n11c & Vaccenic acid & 2.53 & 0.65 \\
C18:2n6c & Linoleic acid & 28.29 & 2.35 \\
C20:0 & Arachidonic acid & 0.34 & 0.01 \\
C22:0 & Behenic acid & 0.70 & 0.02 \\
C24:0 & Lignoceric acid & 0.55 & 0.04 \\
Saturated fatty acids (SFA) & & 40.59 & 3.10 \\
Monounsaturated fatty acids (MUFA) & 31.12 & 2.35 \\
Polyunsaturated fatty acids & & 28.29 & 2.35 \\
\hline
\end{tabular}

\section{Sterol composition}

Many studies have demonstrated that ergosterol and its peroxidation products may give potential health benefits and significant pharmacological activities, including reducing pain related to inflammation, reducing the incidence of cardiovascular disease, and inhibiting cyclooxygenase enzyme (COX), antioxidant, antimicrobial, and antitumor activities [24, 25].

The experiment was performed in triplicate. In the cyclohexane extract of dried mushroom $T$. equestre, three sterols were identified using GC/MS: 5,6-dihydroergosterol, ergosta-4,6,8(14),22-tetraen-3-one, and $\gamma$-ergostenol (fungisterol) (58.92, 27.55, and $13.53 \%$, respectively). The chromatograms were recorded for all of the examined compounds (Fig. 2). Among them, fungisterol is the sterol most commonly found in the fruiting bodies of the fungi. It was possible to determine its presence, e.g., in the following species: A. bisporus, Boletus edulis, Cantharellus tubaeformis, C. cibarius, Flammulina velutipes, Lentinula edodes, Grifola frondosa, and P. ostreatus [24, 25]. Ergosta$4,6,8(14), 22$-tetraen-3-one, which is a compound demonstrating anti-inflammatory activity (inhibiting cyclooxygenase 1 and 2), is also important from the therapeutic point of view. This effect is confirmed by studies of this compound isolated from the G. frondosa species, which is also an edible species [26]. In the T. equestre species, this compound was determined in the smallest amount. In turn, 5,6-dihydroergosterol, which was determined in the largest amount in the examined species, exhibits weak antibacterial activity (this was confirmed on 5,6-dihydroergosterol isolated from the Ganoderma applanatum species) [26].

\section{Antimicrobial activity}

MIC is defined as the minimum concentration of a given substance that can inhibit the growth of a microorganism $[27,28]$. All of the examined extracts were found to
Fig. 2 GC/MS-FID chromatogram of Tricholoma equestre cyclohexane extract: 1 -5,6-dihydroergosterol; 2 - $\gamma$-ergostenol; 3 - ergosta4,6,8(14),22-tetraen-3-one

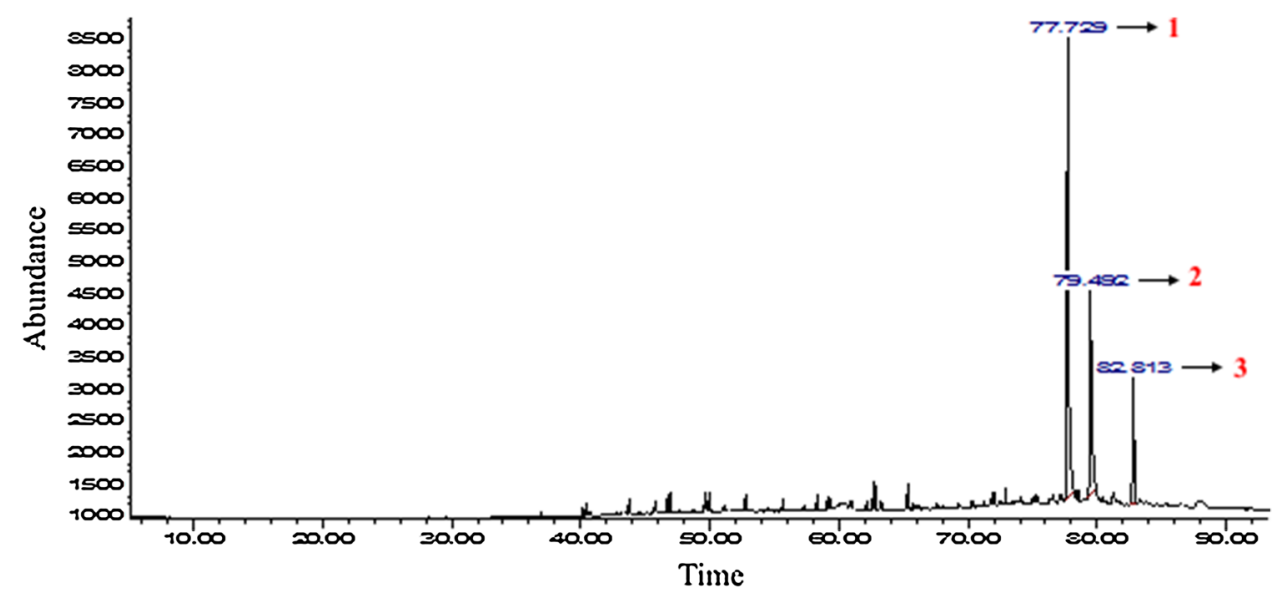


be weakly antibacterial and antifungal (Table 3). MIC values higher than $500 \mu \mathrm{g} / \mathrm{mL}$ indicate a slight activity of these extracts. Among the examined ones, the T. equestre cyclohexane extract turned out to be the most active, particularly with respect to the Staphylococcus aureus (ATCC 25923) and Klebsiella pneumoniae (NCIMB 9111) strains. The MIC values were $250 \mu \mathrm{g} / \mathrm{mL}$ (Table 3). For the sake of comparison, MICs for popular antibiotics are usually from approximately 0.25 to $16 \mu \mathrm{g} / \mathrm{mL}$ [27]. Interestingly, the antimicrobial activity of the T. equestre cyclohexane extract and the T. equestre dichloromethane extract with respect to Staphylococcus aureus (ATCC 25923), Enterococcus faecalis (29212), Escherichia coli (ATCC 10536), and Klebsiella pneumoniae (NCIMB 9111) is still stronger than that of most of the previously examined extracts $[27,28]$. However, the toxicity of the solvents used with respect to the growth of the relevant pathogen strains should be considered, as the aqueous extracts proved to be inactive for all of the strains.

\section{Anti-inflammatory activity}

Data are reported as means \pm SD of at least three independent experiments. Comparisons between treatments were made by a one-way analysis of variance followed by Tukey's post hoc test. Calculations were performed using the Statistica 13.1 (StatSoft Inc., Tulsa, OK, USA) software, and statistical significance was defined as $p<0.05$.

A statistically significant increase in the COX-2 level was observed for cells supplemented with the $T$. equestre extracts $(p=0.000)$ and for LPS-activated A549 cells (threefold; $p=0.000$ ) when compared to the control cells (Fig. 3).

For cPGES, statistically significant differences were noted after the $T$. equestre extract supplementation $(p=0.000)$ and after LPS activation (Fig. 3). The Nrf2 level decreased statistically in cells after treatment with the T. equestre extract $(p=0.000)$ and increased after

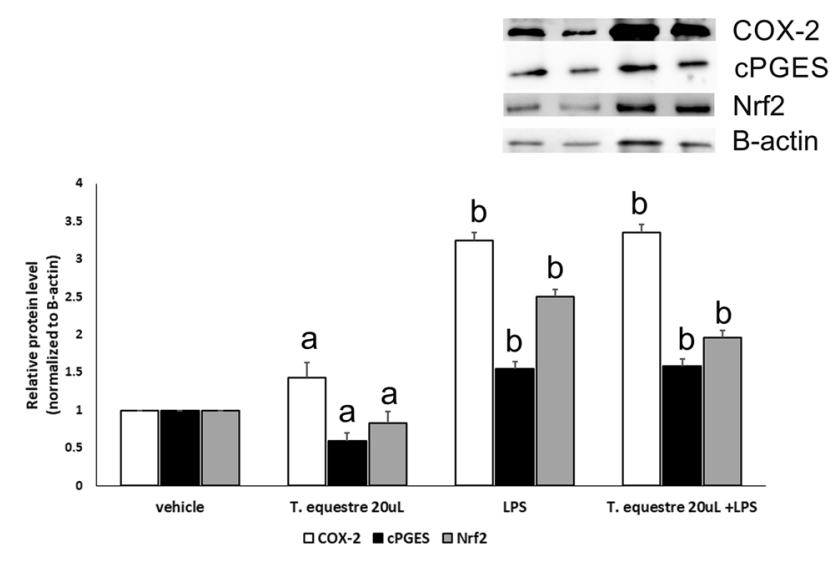

Fig. 3 Relative COX-2, cPGES, and Nrf2 levels in the A549 cells treated with $20-\mu \mathrm{L}$ Tricholoma equestre extracts and/or LPS; $\mathbf{a}, \mathbf{b} \neg$ statistical significant differences, a vs. LPS, b vs. control, $p<0.05$

the LPS activation ( $p=0.001$ ) (Fig. 3). The co-treatment of the A549 cells with the T. equestre extract and LPS resulted in a slight increase in COX-2 and a slight decrease in the Nrf2 level (Fig. 3).

In the present study, differences were observed in the COX-2 and cPGES levels in the A549 cells, those activated by LPS, and those supplemented with the T. equestre extracts. This finding suggested the additive, pro-inflammatory role of the T. equestre extracts on the epithelial cells activated with LPS. Nieminen et al. (2008) reported in mice exposed to $12 \mathrm{~g} / \mathrm{kg} /$ day of $T$. equestre freshly frozen mushroom, higher plasma bilirubin content and higher creatine kinase activity than in the control mice. Moreover, the authors showed an increased incidence of pericardial inflammation in mice after the T. equestre diet [8]. Our study confirmed this observation. Many others species of edible mushrooms presented anti-inflammatory activity [29-31].
Table 3 Minimal inhibitory concentration (MIC)

\begin{tabular}{lllllll}
\hline Bacterial strains & \multicolumn{7}{l}{ MIC $(\mu \mathrm{g} / \mathrm{mL})$} & & \\
\cline { 2 - 7 } & TEA & TEM & TEC & TED & Ampicillin & Amikacin \\
\hline Staphylococcus aureus (ATCC 25,923) & $>500$ & $>500$ & 250 & 500 & 0.5 & - \\
Bacillus subtilis (ATCC 6633) & $>500$ & $>500$ & $>500$ & $>500$ & 1.8 & - \\
Enterococcus faecalis $(29,212)$ & $>500$ & $>500$ & 500 & 500 & - & - \\
Escherichia coli (ATCC 10,536) & $>500$ & $>500$ & 500 & 500 & 2.0 & 1.5 \\
Klebsiella pneumoniae (NCIMB 9111) & $>500$ & $>500$ & 250 & 500 & 2.8 & 2.0 \\
Salmonella abony (NCTC 6017) & $>500$ & $>500$ & $>500$ & $>500$ & - & - \\
Pseudomonas aeruginosa (ATCC 9027) & $>500$ & $>500$ & $>500$ & $>500$ & - & 2.5 \\
Candida albicans (ATCC 10,231) & $>500$ & $>500$ & $>500$ & $>500$ & - & - \\
\hline
\end{tabular}

TEA Tricholoma equestre aqueous extract, TEM Tricholoma equestre methanol extract, TEC Tricholoma equestre cyclohexane extract, TED Tricholoma equestre dichloromethane extract, - not tested 


\section{Conclusion}

T. equestre is a species of mushroom that, when consumed in small quantities, is a source of essential nutrients, particularly bioelements, fatty acids, and sterols. However, when consumed in large quantities, it causes poisoning due to rhabdomyolysis. The present study showed that despite the antioxidant activity comparable to that of the other edible species and the content of nutrients, the T. equestre extracts had a pro-inflammatory effect on the considered cell lines, confirming the danger associated with the consumption of this species. The toxic substance and the mechanism of poisoning remain unexplained; explaining these requires cooperation and further research on the dual nature of this species. Analyzing the content and pro-health potential of the $T$. equestre fruiting bodies and extracts prepared from them, we concluded that these fruiting bodies did not stand out from the edible species with particular pro-health activity. The antioxidant activity, total phenol content, content of elements, and antimicrobial activity remained at a similar or relatively low level as compared to those of the other edible species, whereas the pro-inflammatory activity clearly encouraged the limited consumption of this species. In conclusion, the presented results, in addition to the existing reports on poisoning caused by the consumption of $T$. equestre, are another reason to not take the risk of the consumption of the fruiting bodies of this species, as the natural environment is rich in other species of edible mushrooms that are not only tasty but also have healing properties.

\section{Compliance with ethical standards}

Conflict of interest The authors declare that they have no conflict of interest.

Compliance with ethics requirements This article does not contain any studies with human or animal subject.

Open Access This article is distributed under the terms of the Creative Commons Attribution 4.0 International License (http://creativeco mmons.org/licenses/by/4.0/), which permits unrestricted use, distribution, and reproduction in any medium, provided you give appropriate credit to the original author(s) and the source, provide a link to the Creative Commons license, and indicate if changes were made.

\section{References}

1. Muszyńska B, Piotrowska J, Krakowska A, Gruba A, Kała K, Sułkowska-Ziaja K, Kryczyk A, Opoka W (2017) Study of physiologically active components in different parts of fruiting bodies of varieties of Agaricus bisporus (white mushroom). Eur Food Res Technol 243:2135-2145

2. Diaz JH (2016) Mistaken Mushroom Poisonings. Wilderness Environ Med 27:330-335
3. Kała K, Krakowska A, Sułkowska-Ziaja K, Szewczyk A, Reczyński W, Opoka W, Muszyńska B (2017) Kinetics of extracted bioactive components from mushrooms in artificial digestive juices. Int J Food Prop 20:1796-1817

4. Cervellin G, Comelli I, Benatti M, Sanchis-Gomar F, Bassi A, Lippi G (2017) Non-traumatic rhabdomyolysis: background, laboratory features, and acute clinical management. Clin Biochem 50:656-662

5. Moukha S, Férandon C, Beroard E, Guinberteau J, Castande B, Calla P, Creppy E, Barroso G (2013) A molecular contribution to the assessment of the Tricholoma equestre species complex. Fungal Biol 117:145-155

6. Persson H (2016) Botanical and animal poisons: Mushrooms. Medicine 44:116-119

7. Vannacci A, Baronti R (2002) Mushroom-induced rhabdomyolisis Cortinarius or Tricholoma? Toxicon 40:1063

8. Nieminen P, Kärjä V, Mustonen AM (2008) Indications of hepatic and cardiac toxicity caused by subchronic Tricholoma flavovirens consumption. Food Chem Toxicol 46:781-786

9. Muszyńska B, Sułkowska-Ziaja K, Ekiert H (2009) Indole compounds in fruiting bodies of some selected Macromycetes species and in their mycelia cultured in vitro. Pharmazie 64:479-480

10. Pachón-Peña G, Reyes-Zurita FJ, Deffieux G, Azqueta A, de Cerain AL, Centelles JJ, Creppy EE, Cascante M (2009) Antiproliferative effect of flavomannin-6,6'-dimethylether from Tricholoma equestre on Caco-2 cells. Toxicol 264:192-197

11. Yamaç M, Yıldız D, Sarıkürkcü C, Çelikkollu M, Solak MH (2007) Heavy metals in some edible mushroom. Food Chem 103:263-267

12. Ribeiro B, de Pinho PG, Andrade PB, Baptista P, Valentão P (2009) Fatty acid composition of wild edible mushrooms species: a comparative study. Microchem J 93:29-35

13. Knudsen H, Vesterholt J (2008) Funga Nordica: agaricoid, boletoid and cyphelloid genera. Nordsvamp, Copenhagen

14. Gdula-Argasińska J, Czepiel J, Totoń-Żurańska J, Wołkow P, Librowski T, Czapkiewicz A, Perucki W, Woźniakiewic M, Woźniakiewicz A (2016) n-3 Fatty acids regulate the inflammatory-state related genes in the lung epithelial cells exposed to polycyclic aromatic hydrocarbons. Pharmacoll Rep 68:319-328

15. Sabir SM, Athayde ML, Boligon AA, Rocha JBT (2017) Antioxidant activities and phenolic profile of Baccharis trimera, a commonly used medicinal plant from Brazil. S Afr J Bot 113:318-323

16. Sánchez C (2017) Reactive oxygen species and antioxidant properties from mushrooms. Synth Syst Biotechnol 2:13-22

17. Lee YL, Yen MT, Mau JL (2007) Antioxidant properties of various extracts from Hypsizigus marmoreus. Food Chem 104:1-9

18. Soares AA, de Souza CGM, Daniel F, Ferrari GP, da Costa SM, Peralta RM (2009) Antioxidant activity and total phenolic content of Agaricus brasiliensis (Agaricus blazei Murril) in two stages of maturity. Food Chem 112:775-781

19. Barros L, Ferreira MJ, Queirós B, Ferreira ICFR, Baptista P (2007) Total phenols, ascorbic acid, $\beta$-carotene and lycopene in Portuguese wild edible mushrooms and their antioxidant activities. Food Chem 103:413-419

20. Sulkowska-Ziaja K, Muszynska B, Motyl P, Pasko P, Ekiert H (2012) Phenolic compounds and antioxidant activity in some species of polyporoid mushrooms from Poland. Int J Med Mushrooms 14:385-393

21. Ferreira ICFR, Barros L, Abreu RMV (2009) Antioxidants in wild mushrooms. Curr Med Chem 9:1543-1560

22. Cheung LM, Cheung PCK, Ooi VEC (2003) Antioxidant activity and total phenolics of edible mushroom extracts. Food Chem 81:249-255

23. Lands B (2017) Highly unsaturated fatty acids (HUFA) mediate and monitor food's impact on health. Prostaglandins Other Lipid Mediat 133:4-10 
24. Phillips KM, Ruggio D, Horst RL, Minor B, Simon RR, Feeney MJ, Byrdwell WC, Haytowitz DB (2011) Vitamin D and sterol composition of 10 types of mushrooms from retail suppliers in the United States. J Agric Food Chem 59:7841-7853

25. Sułkowska-Ziaja K, Hałaszuk P, Mastej M, Piechaczek M, Muszyńska B (2016) Mycosteroles-characteristics and biological importance. Med Inter Rev 27:26-34

26. Lindequist U, Niedermeyer THJ, Jülich WD (2005) The pharmacological potential of mushrooms. J Evid Based Complement Altern Med 2:285-299

27. Alves MJ, Ferreira ICFR, Martins A, Pintado M (2012) Antimicrobial activity of wild mushroom extracts against clinical isolates resistant to different antibiotics. J App Microbiol 113:466-475

28. Ramesh CH, Pattar MG (2010) Antimicrobial properties, antioxidant activity and bioactive compounds from six wild edible mushrooms of western ghats of Karnataka, India. Pharmacogn Res 2:107-112

29. Muszyńska B, Sułkowska-Ziaja K, Wołkowska M, Ekiert H (2011) Chemical, pharmacological, and biological characterization of the culinary-medicinal honey mushroom, Armillaria mellea (Vahl) P. Kumm. (agaricomycetideae): a review. Int J Med Mushrooms $13: 167-175$

30. Grzywacz A, Gdula-Argasińska J, Kała K, Opoka W, Muszyńska B (2016) Anti-inflammatory activity of biomass extracts of the Bay mushroom Imleria badia (Agaricomycetes), in RAW 264.7 Cells. Int J Med Mushrooms 18:769-779

31. Muszyńska B, Grzywacz A, Kała K, Gdula-Argasińska J (2018) The Anti-inflammatory potential of in vitro cultures of White Button mushroom, Agaricus bisporus (Agaricomycetes) in CaCo-2 cells. Int J Med Mushrooms 20:129-139 